University of Wollongong

Research Online

Faculty of Informatics - Papers (Archive)

Faculty of Engineering and Information

Sciences

$1-1-2008$

\title{
Output quality evaluation of photovoltaic systems with different current control methods of switch-mode converters
}

\author{
K. N. Hasan \\ University of Tasmania, knhasan@utas.edu.au \\ Md Enamul Haque \\ University of Tasmania, Australia, mehaque@utas.edu.au \\ Michael Negnevitsky \\ University of Tasmania, michael.negnevitsky@utas.edu.au \\ Kashem Muttaqi \\ University of Wollongong, kashem@uow.edu.au
}

Follow this and additional works at: https://ro.uow.edu.au/infopapers

Part of the Physical Sciences and Mathematics Commons

\section{Recommended Citation}

Hasan, K. N.; Haque, Md Enamul; Negnevitsky, Michael; and Muttaqi, Kashem: Output quality evaluation of photovoltaic systems with different current control methods of switch-mode converters 2008, [6].

https://ro.uow.edu.au/infopapers/1685

Research Online is the open access institutional repository for the University of Wollongong. For further information contact the UOW Library: research-pubs@uow.edu.au 


\title{
Output quality evaluation of photovoltaic systems with different current control methods of switch-mode converters
}

\begin{abstract}
This paper presents a comparative assessment of the current control methods (CCM) of switch-mode converters for photovoltaic (PV) applications. In this paper, average current control, current programmed control, hysteresis current control and nonlinear carrier control methods are addressed considering input fluctuations and load variations for PV systems. Dynamic responses of PV systems are investigated and harmonic analysis is performed. Performances of the above current controllers are examined through simulation and the results are presented. The results show that the selection of different current control techniques depends on the working conditions and the area of applications.
\end{abstract}

\section{Keywords}

Output, quality, evaluation, photovoltaic, systems, different, current, control, methods, switch, mode, converters

\section{Disciplines}

Physical Sciences and Mathematics

\section{Publication Details}

K. N. Hasan, M. E. Haque, M. Negnevitsky \& K. M. Muttaqi, "Output quality evaluation of photovoltaic systems with different current control methods of switch-mode converters," in ICHQP 2008: 13th International Conference on Harmonics \& Quality of Power, 2008, p. [6]. 


\title{
Output Quality Evaluation of Photovoltaic Systems with Different Current Control Methods of Switch-Mode Converters
}

\author{
K.N. Hasan, M. E. Haque, Member, IEEE, M. Negnevitsky, Senior Member, IEEE, and K. M. Muttaqi, \\ Senior Member, IEEE
}

\begin{abstract}
This paper presents a comparative assessment of the current control methods (CCM) of switch-mode converters for photovoltaic (PV) applications. In this paper, average current control, current programmed control, hysteresis current control and nonlinear carrier control methods are addressed considering input fluctuations and load variations for PV systems. Dynamic responses of PV systems are investigated and harmonic analysis is performed. Performances of the above current controllers are examined through simulation and the results are presented. The results show that the selection of different current control techniques depends on the working conditions and the area of applications.
\end{abstract}

Index Terms--Current control, dc-dc power conversion, harmonic analysis, photovoltaic power systems, power quality.

\section{INTRODUCTION}

A $\mathrm{S}$ long as the popularity of renewable photovoltaic (PV) energy continues to increase, the power interfaces of PV systems attract more and more concern. Generally, the power interfaces of the PV systems are associated with high cost and low efficiency [1]. Moreover, as the PV power is fully dependent on weather conditions, its control requires reliable regulation. In order to make the PV array power usable, a dcdc conversion stage followed by a dc-ac conversion stage is mostly used. The former stage is responsible for boosting the voltage and ensuring maximum utilization of PV array power while the latter stage is for dc-ac conversion and for load or utility interaction [2]. Both converter and inverter stages have functions regarding the quality of power. Since some electrical appliances are fed with dc power [3], it is better to provide control for dc-dc converters as well as inverters. Fig. 1 shows a block diagram of a typical PV simulation system.

In PV systems, the function of a dc-dc converter is to supply a regulated dc output voltage irrespective of the load variations and/or input fluctuations. The utility ac voltage is usually $230 \mathrm{~V}$ and thus requires a dc voltage of $400 \mathrm{~V}$ at the

K. N. Hasan, M. E. Haque and M. Negnevitsky are with the Centre for Renewable Energy and Power Systems, University of Tasmania, Hobart, TAS 7001 Australia (e-mail: knhasan@utas.edu.au, Enamul.Haque@utas.edu.au, Michael.Negnevitsky@utas.edu.au).

K. M. Muttaqi is with the Integral Energy Power Quality and Reliability Centre at the School of Electrical, Computer and Telecommunication Engineering, University of Wollongong, NSW 2522 Australia (e-mail: kashem@uow.edu.au).

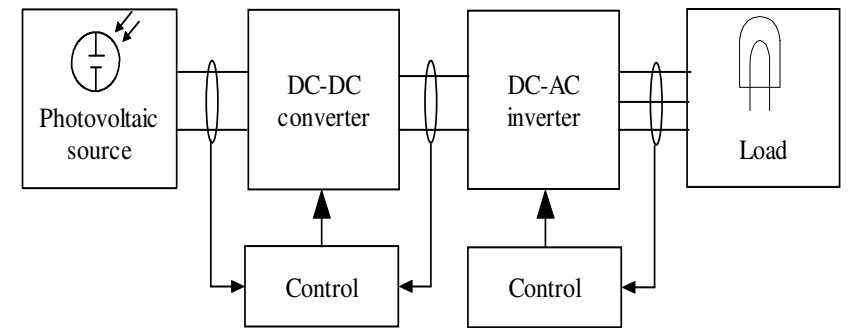

Fig. 1. Block diagram of the simulated PV system.

output of the dc-dc converter. As the PV array voltage is usually below this level, the system boosts up the voltage level using the dc-dc conversion stage or a transformer at the output of the inverter [4]. However, a transformer in the PV system is often associated with significant loss. In addition, transformers obviously add weight and cost, and thus cause a reduction in efficiency of about 2\% [5]. Although buck, boost, buck-boost, Cuk and SEPIC converters can be investigated as a PV interface, it should be noted that the boost converter offers some advantages over other topologies [6]-[8]. Apart from boosting the voltage, the boost converter has a continuous input current and a discontinuous output current which is advantageous for the use in a photovoltaic interface [9].

Since the photovoltaic current and hence the voltage is subjected to rapid and random changes, the dc-dc converter topology and control strategy requires a robust regulation. There are several alternatives available for the control of PV converters. The use of the voltage control method (VCM) for PV power generation systems is investigated in [4]. PV converters with the current control method (CCM) offer good dynamic behavior and stability [10]. As the inductor is on the input side of the boost converter, the CCM can effectively control the input current [9] and gets better control over the input voltage [11].

In this paper, different current control strategies of the dcdc converter for PV applications are investigated to evaluate their performances in order to optimize the operation of the PV systems. This paper is organized as follows: a PV model is presented in Section II; the converter control methods are reviewed in Section III; Section IV deals with different CCMs for the dc-dc converter; simulation results are illustrated in Section V; comparative study of CCMs is presented in Section VI followed by conclusions. 


\section{PV CHARACTERISTICS}

Naturally, solar radiation varies randomly at different times of the day and different seasons of the year. Fig. 2 shows the PV array output power of a specific region [12], which reflects the irregular behavior of solar radiation. A PV module, which converts light into electricity, can be modeled as a single diode model, as shown in Fig. 3. Fig. 3 gives the following equations for different currents and voltages of the equivalent circuit model of the PV module,

$$
\begin{aligned}
& I_{L G}-I_{D}-\frac{V_{D}}{R_{s h}}-I_{p v}=0 \\
& V_{p v}-V_{D}+I_{p v} R_{s}=0
\end{aligned}
$$

where $I_{L G}(\mathrm{~A})$ is the light generated current; $I_{D}(\mathrm{~A})$ is the diode current; $V_{D}(\mathrm{~V})$ is the voltage drop across the diode; $R_{s h}(\Omega)$ is the shunt resistance; $R_{s}(\Omega)$ is the series resistance; $I_{p v}(\mathrm{~A})$ and $V_{p v}(\mathrm{~V})$ are $\mathrm{PV}$ module output current and voltage, respectively.

The operating equation of the PV module can be easily derived as [13],

$I_{p v}=I_{L G}-I_{s a t}\left(e^{\frac{q}{n k T}\left(V_{p v}+I_{p v} R_{S}\right)}-1\right)-\frac{V_{p v}+I_{p v} R_{s}}{R_{s h}}$ (3)

where, $I_{\text {sat }}(\mathrm{A})$ is the PV module saturation current; $T(\mathrm{~K})$ is the PV module temperature and $k$ is Boltzmann constant.

The output characteristics of the PV module are shown in Fig. 4. This figure is exposed to a specified amount of irradiance $\left(1000 \mathrm{Wm}^{-2}\right)$ at a constant temperature $\left(25^{\circ} \mathrm{C}\right)$.

\section{OVERVIEW OF The CONVERTER CONTROL TeChNiQues}

Different converter control techniques are used to obtain a desired output with a high accuracy regardless of disturbances in the input. In addition to extracting the maximum power from the input source, the controller is also responsible for the protection of the converter [14]. To achieve these objectives, the controller uses loops of either the feed-back or feedforward type. Mainly, two types of control strategies exist for converter control: voltage control method (VCM) and current control method (CCM). Figs. 5(a) and (b) show the VCM and CCM systems, respectively as block diagrams.

The VCM senses the output voltage of converter and compares it with a reference voltage. The comparator calculates the error. Then the compensator forms the input to the PWM modulator to provide the switching pulses [4].

Generally, the VCM has a slow response, which makes the VCM redundant in PV applications. Any change in the PV system source or load is first sensed as an output change and then gets corrected by the feedback loop. The loop gain of the VCM also varies with the change in input voltage [15].

In contrast, the CCM uses a pair of nested loops. The outer loop compares the output voltage with a reference voltage whereas the inner loop derives an error signal from the difference of the feed-forward current and the compared resultant voltage of the outer loop. Thus, the error provides the gate signals for switching pulses [4].

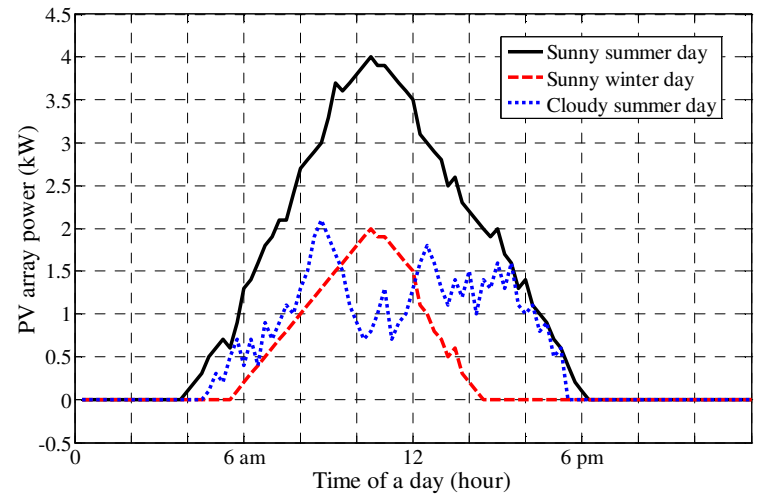

Fig. 2. Available PV array output power over a single day in Sydney, Australia at different environmental conditions [12].

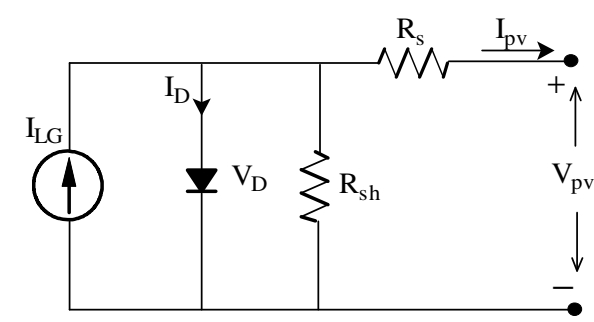

Fig. 3. Equivalent circuit of the PV module.

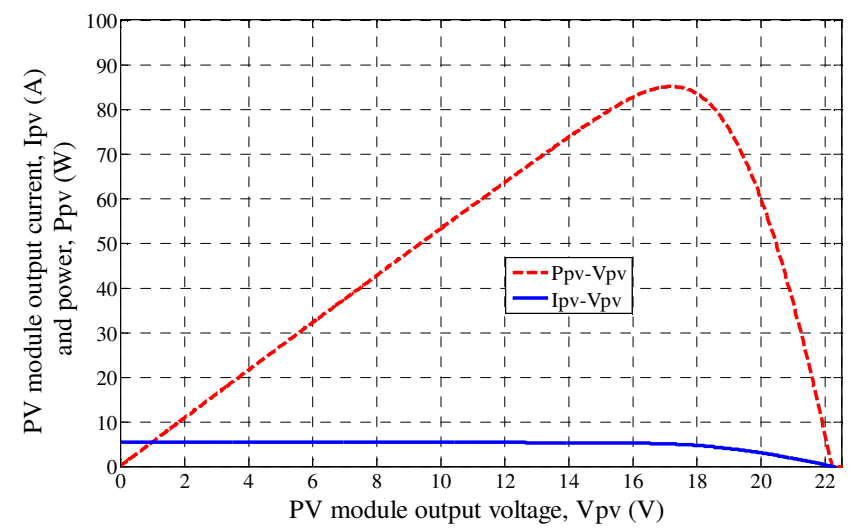

Fig. 4. Current-voltage and power-voltage characteristics of the PV module at a constant temperature and a specified irradiance.

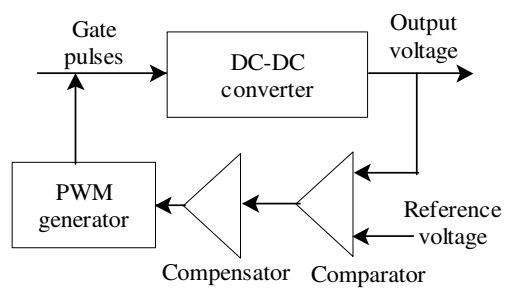

(a)

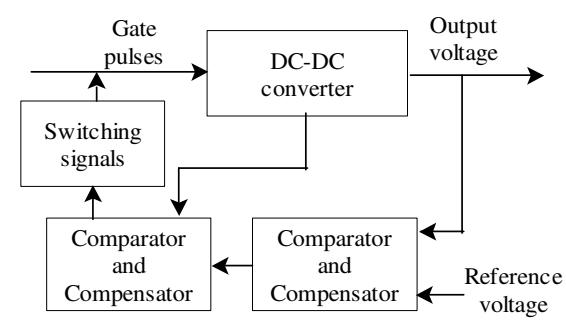

(b)

Fig. 5. Block diagrams of the conventional (a) VCM and (b) CCM. 
The CCM is usually adopted because it exhibits, in general, better safety, better stability and faster response [16]-[21]. The CCM has higher control to output gain and crossover frequency in comparison with the VCM. The closed-loop phase response of the CCM is smoother than that of the VCM. The CCM has a faster response in case of very high speed load transients [16]. Furthermore, no additional circuitry is needed to sense the inductor current as it is already in place from the current feedback loop [19].

\section{The Current Control Methods of The PHOTOVOLTAIC CONVERTERS}

The CCM employs a current feedback loop in addition to the voltage feedback loop. A CCM generally uses the current from an inductor or a switch, as well as the output voltage error signal. Subsequently, it generates input to the PWM modulator or directly gate pulses as switching signals.

Several methods are proposed for active control of the input current of dc-dc converters. The objective of the methods is to attain input resistor emulation [22]. The working principles of the four most popular current control methods are briefly explained and their performances are analyzed and compared.

\section{A. Average Current Control}

The average current control (ACC) method uses the input current and compares it with a reference voltage. A comparison of the voltage, which is proportional to the input current $\left(i_{\mathrm{s}}\right)$, with feedback voltage, produces an error signal to drive the controller and the PWM modulator. Fig. 6 shows the block diagram of the average current control method.

\section{B. Current Programmed Control}

In this method, the converter switch current $\left(i_{\mathrm{sw}}\right)$ is measured and compared with the control current. The control current comes from the feedback loop. The comparator output drives a latch to pass the switching signal. The block diagram of the current programmed control (CPC) is shown in Fig. 7.

\section{Hysteresis Current Control}

The hysteresis current control (HCC) method operates at a variable frequency. The hysteretic controller provides the gating signal for switching on-off as necessary to maintain a waveform within a set limit. The switch is in either ON or OFF position according to the response of the zero current detector (ZCD). The ZCD senses the inductor current ( $\left.\mathrm{i}_{\mathrm{L}}\right)$. Fig. 8 shows the block diagram of the hysteresis current control method.

\section{Nonlinear Carrier Control}

The nonlinear carrier control (NCC) method uses a current transformer to obtain the switch current $\left(\mathrm{i}_{\mathrm{sw}}\right)$, which is then integrated. The output of the integrator is compared with the output of the nonlinear carrier generator. The carrier voltage is generated from the double integration of the feedback voltage. The output of the comparator then goes to the latch which generates gating pulses. The NCC is shown in Fig. 9 as a block diagram.

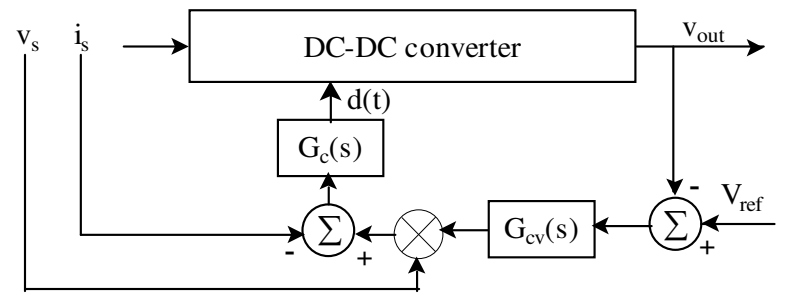

Fig. 6. Average current control method for the control of the converter.

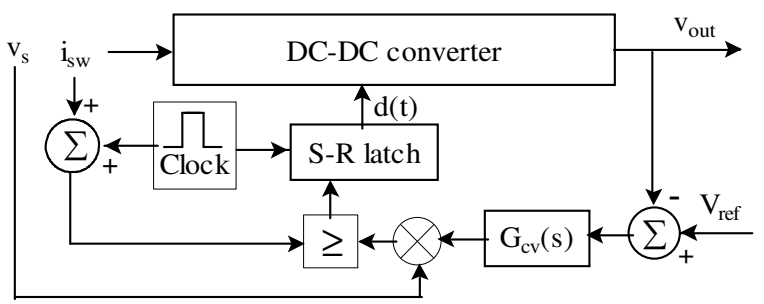

Fig. 7. Current programmed control method for the control of the converter.

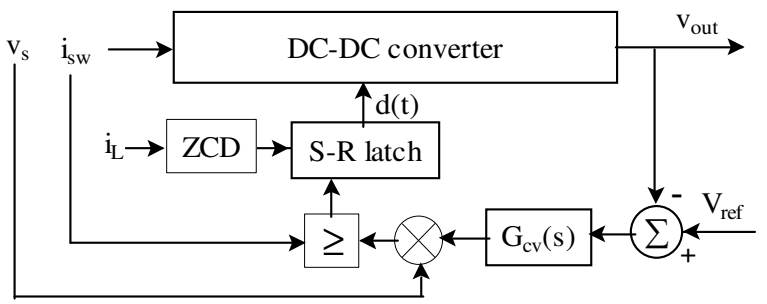

Fig. 8. Hysteresis current control method for the control of the converter.

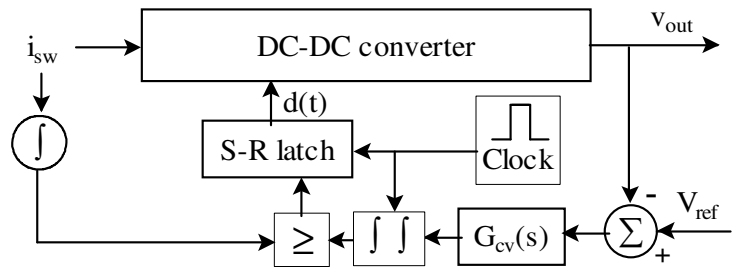

Fig. 9. Nonlinear carrier control method for the control of the converter.

\section{Simulation Results and Performance Evaluation of DIFFERENT CURRENT CONTROL METHODS}

A simulation model has been developed using MATLAB/Simulink dynamic system simulation software. A Simulink model of a PV module, shown in Fig. 10, is used as the PV source [23]. This model takes solar irradiance and PV module current as input and gives PV module voltage and power as the output. Different parameters of the circuit, such as short circuit current, open circuit voltage, current and voltage at maximum power point (MPP) can also be set in the model. The dc-dc converter of the system is designed for $200 \mathrm{~V}$ dc input voltage, which can be boosted up to $400 \mathrm{~V}$ dc at the output. The inverter output provides a $230 \mathrm{~V}, 50 \mathrm{~Hz}$ voltage while $2 \mathrm{~kW}$, 3-phase parallel RLC load is fed by the PV system. The simulation model is designed according to the system power capability requirements. Table I shows the specifications of the system. 
The responses of $\mathrm{PV}$ power conversion systems with different current control techniques are obtained through simulations. Figs. 11-16 show the simulation results of PV power conversion systems using the four current control techniques as discussed earlier. System stability, transient response and power quality (PQ) issues are also investigated.

\section{A. Effect of Control on Converter Output Voltage}

Fig. 11 shows the output voltage responses of the dc-dc boost converters for PV applications simulated with four different CCMs. The ACC and CPC have a very high percentage of overshoot, at $81 \%$ and $95 \%$, respectively. The hysteresis current control method offers a low overshoot and small fluctuations at the output voltage. The nonlinear carrier control method also has no overshoot though it contains some ripple at the output voltage. It is noted that, the ACC (395V), CPC (398V) and NCC (405V) can support the desired 400V output voltage level at the converter output, while the HCC (373V) is far below this level.

\section{B. Effect of Control on Dynamic Performances}

Dynamic responses of the CCMs are presented in Fig. 12. To investigate the dynamic performances, loads are disconnected at a time instant of $0.6 \mathrm{sec}$. and then reconnected at the time instant of $0.7 \mathrm{sec}$. By this time, the ACC offers a voltage fluctuation of $29 \%$ below and $34 \%$ above its steady state value. For the CPC, the voltage goes down by $33 \%$ and rises to $53 \%$ of average dc level. The HCC (27\% below and $40 \%$ above) and NCC (53\% below and $15 \%$ above) also suffer significant fluctuations in the output voltage during dynamic response analysis.

\section{Effect of Input Variations on Control Schemes}

The simulation platform is designed for the PV system with $200 \mathrm{~V}$ input to the dc-dc converter. Fig. 13 shows the output voltage of the converter for a $\pm 10 \%$ input variation from the specified limit. The HCC offers the best performance for input variations. For a $\pm 10 \%$ input voltage variation, the output voltage of the dc-dc converter changes by $2 \%$ for the ACC and by $3 \%$ for the CPC. The output voltage of the HCC changes by $1.5 \%$ and for the NCC it is $2.6 \%$ with ripples.

\section{Effect of Load Changes on Control Schemes}

To investigate the impact of load variations on the performance of the control strategy of dc-dc converter for PV systems, the load is changed from $1 \mathrm{~kW}$ to $3 \mathrm{~kW}$ (Fig. 14). Initially, a $3 \mathrm{~kW}$ load is fed by the PV system. Then, at 0.4 sec., a $1.5 \mathrm{~kW}$ load is connected to the system. At this time, the voltage level rises by $20 \%$ for both the HCC and NCC. For the ACC and CPC, some fluctuations occur at the output voltage. At the time of $0.6 \mathrm{sec}$, a $1 \mathrm{~kW}$ load is connected to the system. There is no significant change of voltage at this load variation. At the time of $0.8 \mathrm{sec}$., the system returns to supply a $3 \mathrm{~kW}$ load. The simulation result suggests that the HCC and the NCC is the most responsive with load changes. On the other hand, the CPC shows the best performance with load fluctuations. The ACC also performs well with modified loads.

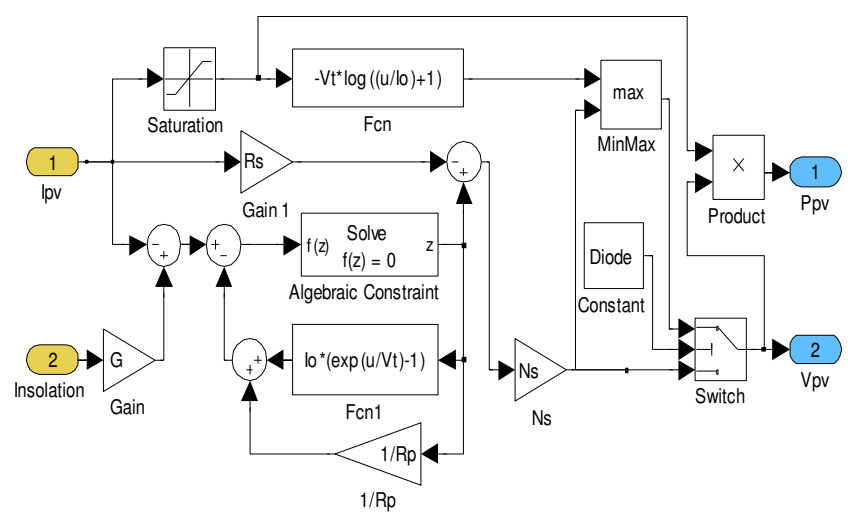

Fig. 10. Simulink model of the PV module [23].

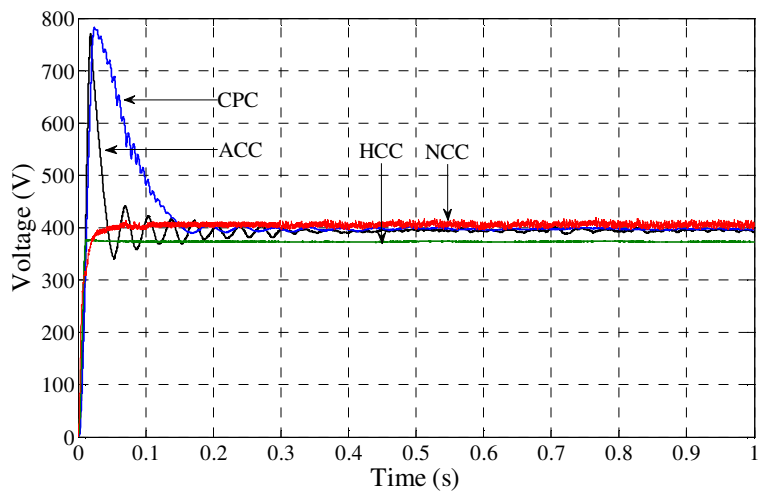

Fig. 11. Output voltage of photovoltaic boost converter with different CCMs.

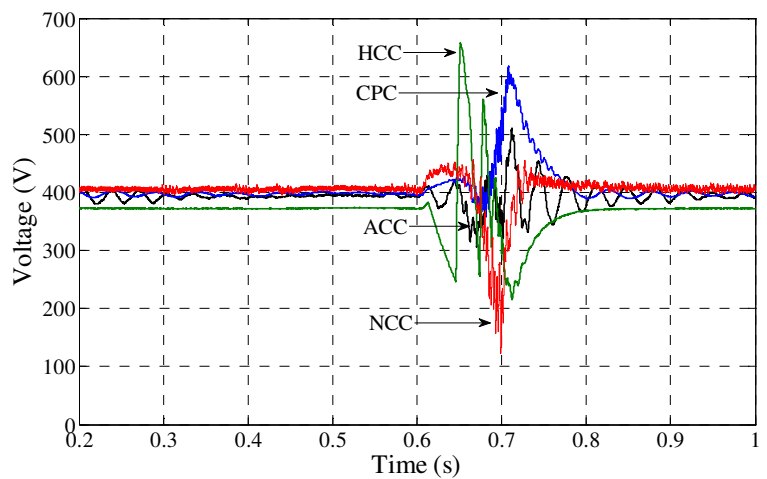

Fig. 12. Dynamic response of photovoltaic boost converter with different CCMs.

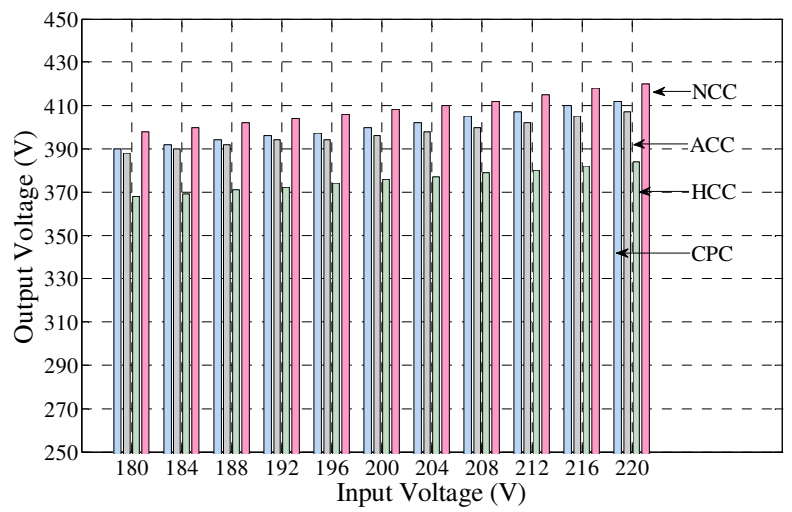

Fig. 13. Effects of input variations on photovoltaic boost converter with different CCMs 


\section{E. Effect of External Disturbances on Control Schemes}

The disappearance of sunlight for a short time due to cloud is a common event. With sudden external disturbances, such as the input voltage falls to zero and then recovers, the CPC $(345 \mathrm{~V}-440 \mathrm{~V})$ offers the best result, as shown in Fig. 15. In this case, the NCC (80V-430V) shows the worst performance. The performance of the ACC (180V-580V) and the HCC (215V$374 \mathrm{~V})$ are also not satisfactory.

\section{F. Effect of Control on Inverter Harmonics}

The total harmonic distortion (THD) is an important factor of the PV power systems since switching actions and power electronic interfaces are associated with these systems. Simulation study reveals that the simulated system offers THD below the IEEE standard recommended limits (THD $<5 \%$ ) [24]. The HCC shows the best performance regarding THD whereas the ACC has the highest THD among all of the observed current control methods.

\section{COMPARATIVE ANALYSIS OF The CuRRENT CONTROL METHODS}

Table II represents different power quality (PQ) issues of PV systems associated with four different CCMs. It is shown that the ACC has very high overshoot and the highest THD. This control method performs well during transient response and in case of sudden load changes. The ACC and NCC provides high ripple $(6 \%)$ in converter output voltage. The ACC has the highest settling time $(0.45 \mathrm{~s})$ while the NCC reaches very fast to its final steady state value. The CPC shows good performance in case of input variations, load changes and external disturbances. Overshoot is very high for the CPC. It offers the worst dynamic performance. On the other hand, the HCC provides very low percentage of overshoot. The HCC also shows a promising result regarding input variations. The response of the HCC is the worst with load changes. The NCC is not suitable for input variations, load changes and external disturbances. Table II reveals that the output voltage of inverter is within the desired band limit for all of the current control methods. Simulation results demonstrate that the THD remains within acceptable limits for all four methods although the HCC provides the best performance $(2.33 \%)$.

\section{CONCLUSIONS}

This paper has investigated the performances of different control methods of dc-dc converter controller for PV power systems in various operating conditions. A PV system is modeled and different controllers are implemented using MATLAB/Simulink. The performances of the ACC, CPC, HCC, and NCC techniques have been analyzed and compared. Transient response and power quality issues of the PV systems operated with different current controllers at different working conditions have been investigated. Effects of input variations, load fluctuations and external disturbances have also been analyzed. It is evident from the simulation study that none of the control method can offer an ideal solution. The control techniques can be selected based on the working conditions.

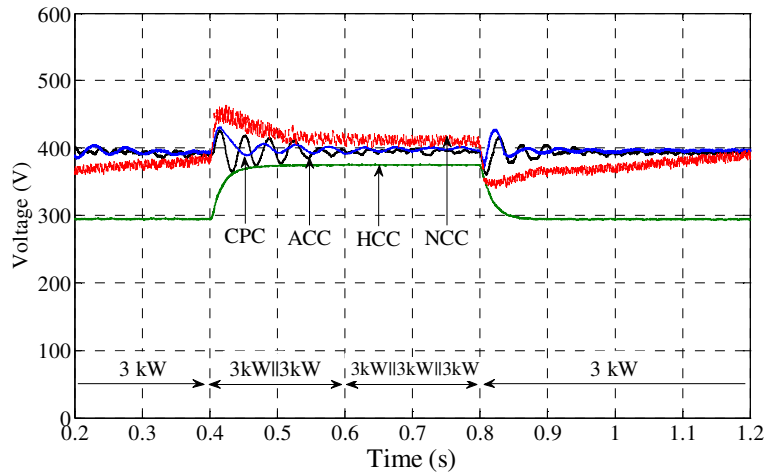

Fig. 14. Effects of load changes on photovoltaic boost converter with different CCMs.

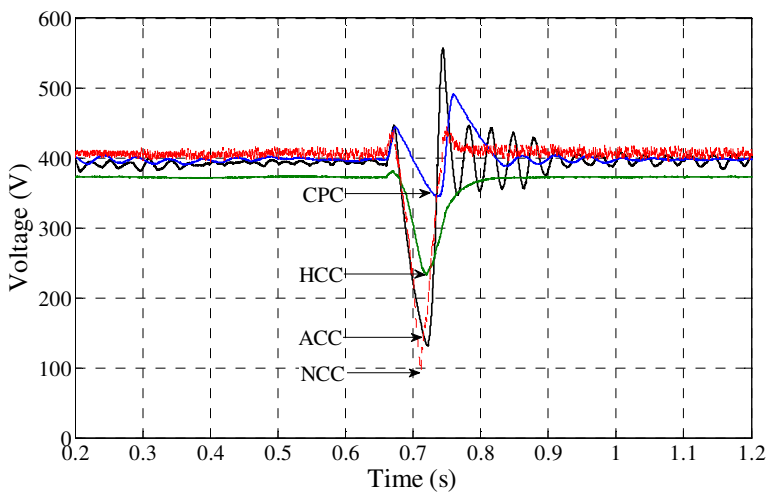

Fig. 15. Effects of external disturbances on photovoltaic boost converter with different CCMs.

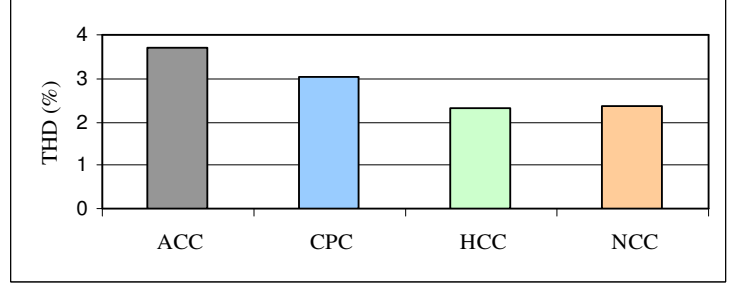

Fig. 16. THD at the output of the inverter with different CCMs.

TABLE I

SYSTEM SPECIFICATIONS

\begin{tabular}{|l|c|}
\hline Input voltage range & $180 \sim 220 \mathrm{~V}$ \\
\hline Converter switching frequency & $25 \mathrm{kHz}$ \\
\hline Converter mode & Continuous conduction \\
\hline Inductor value & $10 \mathrm{mH}$ \\
\hline Capacitor value & $500 \mu \mathrm{F}$ \\
\hline Converter output Resistance & $50 \Omega$ \\
\hline Converter output voltage & $400 \mathrm{~V}$ \\
\hline Inverter output voltage & $230 \mathrm{~V} \mathrm{rms}, 50 \mathrm{~Hz}$ \\
\hline
\end{tabular}

TABLE II

COMPARATIVE ANALYSIS OF DIFFERENT CURRENT CONTROL METHODS

\begin{tabular}{|c|c|c|c|c|c|}
\hline $\begin{array}{c}\text { Criterion } \\
\Omega\end{array}$ & $\begin{array}{l}\text { Control } \\
\Rightarrow\end{array}$ & ACC & CPC & $\mathrm{HCC}$ & NCC \\
\hline \multicolumn{2}{|c|}{ Converter output (V) } & 395 & 398 & 373 & 405 \\
\hline \multicolumn{2}{|c|}{ Converter output ripple (V) } & 6 & 2 & 1.5 & 6 \\
\hline \multicolumn{2}{|c|}{ Delay time $(\mathrm{sec})$} & 0.008 & 0.009 & 0.006 & 0.0045 \\
\hline \multicolumn{2}{|c|}{ Rise time (sec) } & 0.009 & 0.011 & 0.011 & 0.025 \\
\hline \multicolumn{2}{|c|}{ Settling time $(\mathrm{sec})$} & 0.45 & 0.17 & 0.12 & 0.04 \\
\hline \multicolumn{2}{|c|}{$\%$ Overshoot } & 81 & 95 & 0.8 & no \\
\hline \multicolumn{2}{|c|}{ Inverter output (V) rms } & 284 & 280.7 & 263.4 & 246.7 \\
\hline \multicolumn{2}{|c|}{ THD of the inverter (\%) } & 3.69 & 3.04 & 2.33 & 2.35 \\
\hline
\end{tabular}




\section{REFERENCES}

[1] Y. Huang, M. Shen, F. Z. Peng, and J. Wang, "Z-source inverter for residential photovoltaic systems," IEEE Trans. Power Electronics, vol. 21, no. 6, pp. 1776-1782, Nov. 2006.

[2] N. Mutoh and T. Inoue, "A control method to charge series-connected ultra-electric double-layer capacitors suitable for photovoltaic generations combining MPPT control method," IEEE Trans. Industrial Electronics, vol. 54, no. 1, pp. 374-383, Feb. 2007.

[3] K. Kobayashi, H. Matsuo, and Y. Sekine, "Novel solar-cell power supply system using a multiple-input dc-dc converter," IEEE Trans. Industrial Electronics, vol. 53, no 1, pp. 281-286, Feb. 2006.

[4] J.A. Gow and C.D. Manning, "Photovoltaic converter system suitable for use in small scale stand-alone or grid connected applications," in Proc. 2000 IEE Electrical Power Applications, vol. 47, no. 6, pp. 535543.

[5] A. Mohammed, "Control intelligence improves renewable energy efficiency," Power Electronics Technology Magazine, Sep. 2007. [Online]. Available: www.powerelectronics.com

[6] C. Hua and C. Shen, "Control of dc/dc converters for solar energy system with maximum power tracking," in Proc. 1997 IEEE Industrial Electronics, Control and Instrumentation Conf., pp. 827-832.

[7] G. R. Walker and P. C. Sernia, "Cascaded dc-dc converter connection of photovoltaic modules," IEEE Trans. Power Electronics, vol. 19, no. 4, pp. 1130-1139, July 2004.

[8] W. Xiao, N. Ozog, and W. G. Dunford, "Topology study of photovoltaic interface for maximum power point tracking," IEEE Trans. Industrial Electronics, vol. 54, no. 3, pp. 1696-1704, June 2007.

[9] L. Dixon, "Average current mode control of switching power supplies," [Online]. Available: www.colorado.edu/ ecen5807/course_material /papers/cpm/dixon_1990.pdf

[10] R. Li, A. Pottharst, N. Frohleke, and J. Bocker, "Analysis and design of improved isolated full-bridge bi-directional dc-dc converter," in Proc. 2004 IEEE Power Electronics Specialist Conf., pp. 521-526.

[11] J. P. Lee, B. D. Min, T. J. Kim, D. W. Yoo, and B. K. Lee, "A novel topology for photovoltaic series connected $\mathrm{dc} / \mathrm{dc}$ converter with high efficiency under wide load range," in Proc. 2007 IEEE Power Electronics Specialists Conf., pp. 152-155.

[12] Resource book of Australian CRC for Renewable Energy Ltd., Photovoltaic Power Systems: NUER02 Edition, Apr. 2003, p. 8, unit 7.

[13] M. Park and In-K. Yu, "A novel real-time simulation technique of photovoltaic generation systems using RTDS," IEEE Trans. Energy Conversion, vol. 19, no. 1, pp 164-169, Mar. 2004

[14] F. Blaabjerg, R. Teodorescu, M. Liserre, and A. V. Timbus, "Overview of control and grid synchronization for distributed power generation systems," IEEE Trans. Industrial Electronics, vol. 53, no. 5, pp. 13981409, Oct. 2006.

[15] R. Mammano, "Switching power supply topology: voltage mode vs. current mode",[Online].Available:http://focus.ti.com./lit/an/slua119.pdf

[16] B. Lynch, "Current-mode vs. voltage-mode control in synchronous buck converters," [Online]. Available: www.analogzone.com/pwrt0407.pdf

[17] M. P. Kajmierkowski, R. Krishnan, and F. Blaabjerg, "Control in Power Electronics Selected Problems". Academic Press, 2002

[18] M. H. Rashid, Power Electronics Circuits, Devices, and Applications, 3rd ed., Prentice Hall, 2004, p. 627.

[19] M. Hartman, "Inside current-mode control," National Semiconductor. [Online]. Available: www.national.com/appinfo/power/files/Power Designer_106.Pdf

[20] N. Mohan, T. M. Undeland, and W. P. Robbins, Power Electronics Converters, Applications, and Design, 2nd ed., Wiley, 1995, p. 340.

[21] H. M. Kojabadi, B. Yu, I. A. Gadoura, L. Chang, and M. Ghribi, "A novel DSP-based current-controlled PWM strategy for single phase grid connected inverters," IEEE Trans. Power Electronics, vol. 21, no. 4, pp. 985-993, July 2006.

[22] R. W. Erickson and D. Maksimovic, Fundamentals of Power Electronics, 2nd ed., Kluwer Academic Publishers, 2001, p. 648.

[23] PV module Simulink models. [Online]. Available: http://ecewww.colorado.edu/ ecen2060/matlab.html

[24] IEEE Recommended Practices and Requirements for Harmonic Control in Electrical Power Systems, IEEE Standard 519-1992.

\section{BIOGRAPHIES}

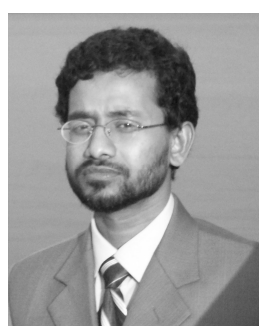

Kazi Nazmul Hasan was born in Gazipur, Bangladesh, on January 25, 1984. He has graduated in Electrical and Electronic Engineering from Bangladesh University of Engineering and Technology (BUET), Bangladesh in 2006. He has worked as trainee engineer for Huawei Technologies (Bangladesh) Ltd. on telecommunication networks. $\mathrm{He}$ is now a postgraduate research student in the School of Engineering, University of Tasmania, Australia. His current research topic is 'DSP-based control of solar power system'. His research interests include solar power generation system, renewable energy applications, DSP based control of power converters, design and control of inverters etc.

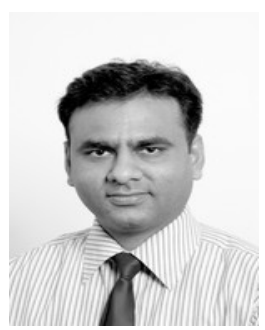

Md Enamul Haque (M'97) graduated in electrical and electronic engineering from Rajshahi University of Engineering and Technology (Formerly BITR) Bangladesh, in 1995. He received the M.Eng. degree from University Technology Malaysia in 1998 and $\mathrm{PhD}$ from University of New South Wales, Sydney, Australia, in 2002. He worked as an assistant professor for King Saud University, Saudi Arabia and United Arab Emirates University, UAE. Now he is working as a lecturer in the school of Engineering of University of Tasmania, Australia. Dr Haque is a regular reviewer of IEEE Transaction on Industrial Electronics and IEEE conferences. He has published 35 international Journal and Conference papers. His research interests include power electronics \& DSP based motor drives, distributed and renewable power generations, power quality and EMI issues.

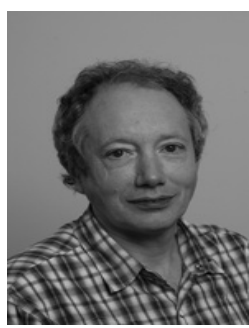

Michael Negnevitsky (M'95, SM'07) received the B.S.E.E. (Hons) and Ph.D. degrees from Byelorussian University of Technology, Minsk, Belarus in 1978 and 1983, respectively. Currently, he is a Professor in the School of Engineering at the University of Tasmania, Hobart, Australia. Professor Negnevitsky authored and co-authored over 250 research publications including 41 refereed journal papers, over 150 conference papers, 10 chapters in books, 2 books, 6 edited conference proceedings and 4 patents for inventions (USSR). Professor Negnevitsky is a Fellow of the Institution of Engineers Australia, Chartered Professional Engineer, Member of the IEEE/PES Intelligent Systems Subcommittee, and Member of the IEEE/PES Task Force on Intelligent Data Mining and Analysis. His interests are on power system analysis, power quality, and intelligent systems applications in power systems.

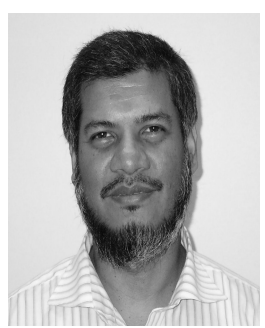

Kashem M. Muttaqi (A'00, SM'05) received the $\mathrm{PhD}$ degree from Multimedia University, Malaysia in 2001. Currently, he is an Associate Professor at the School of Electrical, Computer and Telecommunications Engineering, University of Wollongong, Australia. He is a member of the Integral Energy Power Quality and Reliability Centre. He was associated with the School of Engineering, University of Tasmania, Australia as a Lecturer/Senior Lecturer from 2003 to 2007 and with the Queensland University of Technology as a Postdoctoral Research Fellow from 2000 to 2002. Previously, he also worked for Multimedia University as a Lecturer for three years. His special fields of interests include distributed generation, renewable energy, distribution system automation, power system planning, intelligent grid, power quality and reliability. 